\title{
Fabrication and Optical Characterization of CdSe Thin Films Grown by Chemical Bath Deposition
}

\author{
İ.A. KARiPER ${ }^{a}$, Ö. BAĞLAYAN ${ }^{b}$ AND F. GÖDE ${ }^{c, *}$ \\ ${ }^{a}$ Erciyes University, Primary Education Department, Kayseri, Turkey \\ ${ }^{b}$ Anadolu University, Physics Department, Eskişehir, Turkey \\ ${ }^{c}$ Mehmet Akif Ersoy University, Physics Department, Burdur, Turkey
}

\begin{abstract}
Cadmium selenide thin films with different $\mathrm{pH}$ values $(\mathrm{pH}=10,11,12$ and 13$)$ are produced on glass substrates at $50{ }^{\circ} \mathrm{C}$ for $3 \mathrm{~h}$ by chemical bath deposition technique. The structural, morphological and optical properties of the films are characterized by X-ray diffraction, scanning electron microscopy and optical absorption spectroscopy, respectively. The obtained films have hexagonal structure. The optical transparency of the films varies between $85 \%$ and $98 \%$ at wavelength of $\lambda=550 \mathrm{~nm}$. The scanning electron microscopy studies show that the film deposited at $\mathrm{pH}=10$ exhibits the formation of nanorods in the width range from $1.8 \mu \mathrm{m}$ to $10.9 \mu \mathrm{m}$ and length range from $20.0 \mu \mathrm{m}$ to $85.5 \mu \mathrm{m}$. The optical properties of the films are determined by measuring transmittance and absorbance characteristics which are used to find the optical band gap energy, refractive index, extinction coefficient and real dielectric constant. The band gap width of the films increases from $1.70 \mathrm{eV}$ to $2.30 \mathrm{eV}$ with increasing $\mathrm{pH}$ values. The refractive index of the film at $\mathrm{pH}=10$ is found as 1.54 .
\end{abstract}

DOI: 10.12693/APhysPolA.128.B-219

PACS: 68.37.Hk, 68.55.-a, 78.20.Ci, 81.10.Dn

\section{Introduction}

Cadmium selenide (CdSe) thin films as II-VI group semiconductor are an important research field because of their wide application in various fields of optoelectronic devices. This is due to their high transparency, wide and direct band gap width $(1.74 \mathrm{eV})$, photoconductivity, high electron affinity and $n$-type conductivity. They can be crystallized in hexagonal, cubic or mixed (hexagonalcubic) forms. These films have potential applications in many semiconductor devices such as thin film transistors [1], light emitting diodes [2, 3], gas sensors [4] and solar cells [5, 6], etc.

Due to its tunable band gap, CdSe can vary its optical response from the infrared region to the ultraviolet using different deposition techniques, such as electrochemical [7], successive ionic layer adsorption and reaction (SILAR) [8], molecular beam epitaxy (MBE) [9], solvothermal [10] and chemical bath deposition (CBD) [11], etc. The CBD method for the deposition of thin films from an aqueous solution is a promising technique because of its simplicity, affordability, convenience for large-scale deposition and having easily-controllable parameters such as concentration, $\mathrm{pH}$, deposition temperature and deposition time, etc. The preparation conditions such as solution concentration, $\mathrm{pH}$ value, deposition time and bath temperature are optimized in order to get good quality of CdSe thin films.

The aim of the present work is the investigation of the structural, morphological and optical properties of CdSe

*corresponding author; e-mail: ftmgode@gmail.com thin films which are produced on glass substrates at $50^{\circ} \mathrm{C}$ for $3 \mathrm{~h}$ by CBD method. In this respect, the refractive index, extinction coefficient and dielectric constant are determined from the transmittance and absorbance measurements.

\section{Experimental}

In the present study, the first step is the preparation of selenium source. Hence, $0.01 \mathrm{~mol}$ solid selenium, $20 \mathrm{~mL}$ concentrate $1-4$ dioxane and $0.01 \mathrm{~mol} \mathrm{KOH}$ were sequentially put into a beaker. The resulting mixture was heated up to $80^{\circ} \mathrm{C}$ in order to evaporate $1-4$ dioxane. After it was completely evaporated, $\mathrm{KOH}+$ Se gel remained at the bottom of the beaker. $0.01 \mathrm{~mol} \mathrm{LiAlH}_{4}$ was immediately added to the beaker before the gel got cold. (Adding $\mathrm{LiAlH}_{4}$ requires a great care since the reaction is flammable.) The final volume was completed to $100 \mathrm{ml}$ by adding deionized water. The final $\mathrm{pH}$ of the solution was measured as 13 . The mixture was filtered before adding to the chemical bath.

The second step is the preparation of the chemical bath in order to produce semiconductor CdSe thin films as follows: $5 \mathrm{~mL}$ of $0.001 \mathrm{M}$ cadmium nitrate, $5 \mathrm{~mL}$ of the prepared Se source solution, $5 \mathrm{~mL}$ triethanolamine (TEA) and $40 \mathrm{~mL}$ deionized water. The final solution $\mathrm{pH}$ was measured as $13 . \mathrm{HCl}(8 \%)$ was used to adjust the $\mathrm{pH}$ of the bath as 10,11 and 12. The reaction bath was put into the oven at $50^{\circ} \mathrm{C}$ for $3 \mathrm{~h}$. The CdSe films were obtained from an aqueous alkaline bath containing cadmium salt as $\mathrm{Cd}^{2+}$ source and selenide salt as $\mathrm{Se}^{2-}$ source. The reaction of CdSe formation on the glass substrates is expressed as follows:

$$
\mathrm{Se}_{(\mathrm{k})}+2 \mathrm{e}^{-\stackrel{\mathrm{LiAlH}_{4}}{\longleftrightarrow} \mathrm{Se}_{(\mathrm{aq})}^{-2}},
$$




$$
\mathrm{Cd}_{(\mathrm{aq})}^{+2}+\mathrm{Se}_{(\mathrm{aq})}^{-2} \rightarrow \mathrm{CdSe}_{(\mathrm{k})}
$$

The thickness of the films determined by the gravimetric weight difference method varies between $465 \mathrm{~nm}$ and $605 \mathrm{~nm}$. A sensitive microbalance is used to measure weight and the film density is assumed to be uniform and as dense as bulk CdSe with a density of $5.674 \mathrm{~g} \mathrm{~cm}^{-3}$. The crystalline structure of the films are confirmed by using X-ray diffractometer (XRD) model Rigaku RadB in the scanning angle $(2 \theta)$ range of 10-90 degrees with $\mathrm{Cu} K_{\alpha}$ radiation with a wavelength of $\lambda=1.54056 \AA$. The morphology of the films is examined by scanning electron microscopy (SEM; EVO40-LEO). The optical absorption and transmission spectra of the films are measured by a UV-Vis spectrophotometer (Hach Lange 500) within the wavelength of 300-1100 nm.

\section{Results and discussions}

Figure 1 shows the XRD patterns of the CdSe thin films deposited at different $\mathrm{pH}$ values. As can be seen from this figure, all deposited films have an amorphous structure. The broad hump between $15^{\circ}$ and $40^{\circ}$ is due to amorphous nature of the CdSe thin films. When compared these data with the standard $2 \theta$ and $d$ values, it can be concluded that the obtained films are hexagonal CdSe (PDF No. 08-0459) structure. Moreover, the XRD results are in agreement with reported data [12].

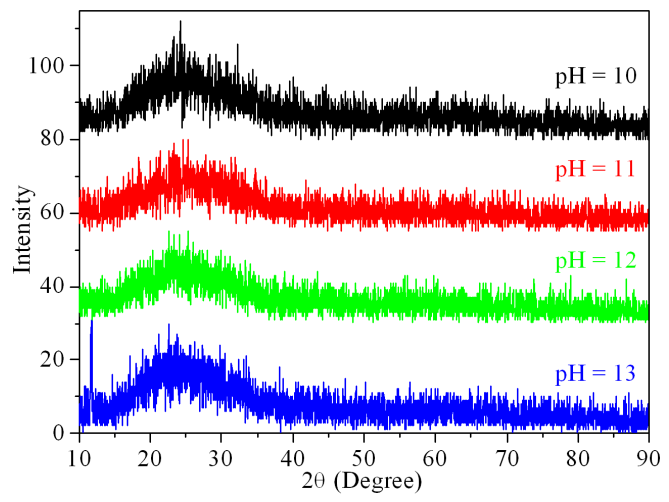

Fig. 1. X-ray diffraction patterns for CdSe thin films grown with different $\mathrm{pH}$ values.

It is known that the surface properties of the films influence their optical properties and are very important in applications of optoelectronic devices. Figure 2 shows the surface morphology of the CdSe thin films produced at different $\mathrm{pH}$ values. The SEM image in Fig. 2a indicates the formation of nanorods in CdSe thin films. These nanorods are aligned in different directions. The observed nanorods seem to be in width range from $1.8 \mu \mathrm{m}$ to $10.9 \mu \mathrm{m}$ and length range from $20.0 \mu \mathrm{m}$ to $85.5 \mu \mathrm{m}$. Moreover, these nanorods are broken when the $\mathrm{pH}$ of the bath is increased to 11,12 and 13 in Fig. 2b-d, respectively. In comparison with CdSe films obtained at $\mathrm{pH}=11,12$ and 13, it can be concluded that we have achieved to produce CdSe nanorods with the $\mathrm{pH}=10$.

The optical transmittance $(T \%)$, absorption $(A)$ and reflectance $(R \%)$ spectra for CdSe thin films are
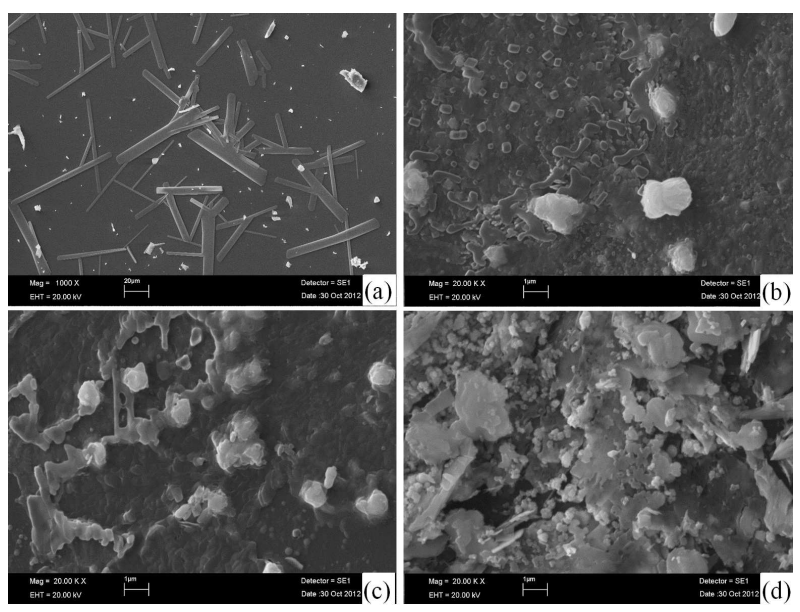

Fig. 2. SEM images of CdSe thin films with the magnification of $20000 \times$ at different $\mathrm{pH}$ values (a) 10, (b) 11 , (c) 12 and (d) 13 .
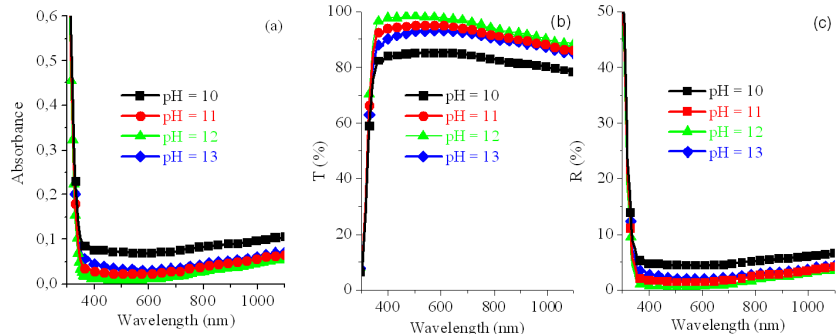

Fig. 3. (a) The absorbance, (b) transmittance and (c) reflectance spectra of CdSe thin films at different $\mathrm{pH}$.

represented in Fig. 3a-c, respectively. It is seen from Fig. 3b that the optical transparency of deposited films varies between $85 \%$ and $98 \%$ at wavelength of $\lambda=550 \mathrm{~nm}$.

The absorption coefficient $(\alpha)$ is given by the relation

$$
T=(1-R) \exp (-\alpha t),
$$

where $t$ is the film thickness. The absorption coefficient data are used to evaluate the band energy width $\left(E_{\mathrm{g}}\right)$ using the relation [3]:

$$
(\alpha h \nu)^{2}=B\left(h \nu-E_{\mathrm{g}}\right),
$$

where $B$ is a proportionality constant. From the $(\alpha h \nu)^{2}$ vs. $(h \nu)$ plot, the optical band gap width is determined by extrapolating the linear portion of the graph shown in Fig. 4. It can be seen that the direct band width of the film increases from $1.70 \mathrm{eV}$ to $2.30 \mathrm{eV}$ with increasing $\mathrm{pH}$. The optical band gap values are in good agreement with the reported values [11-14]. An increase in the band gap width can be attributed to the quantum confinement effect [15] due to the small grain size in the CdSe thin films with increasing $\mathrm{pH}$.

The knowledge of the optical parameters such as refractive index $(n)$, extinction coefficient $(k)$ and dielectric constant $(\varepsilon)$, over a wide wavelength range and optical band gap values of semiconducting films is quite important to predict the photoelectrical behaviour of a device. 


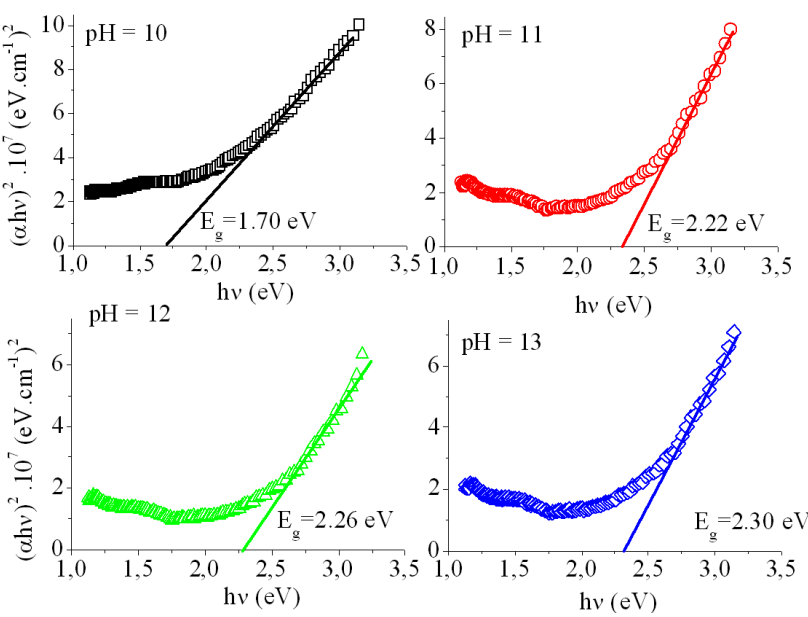

Fig. 4. Plot of $(\alpha h \nu)^{2}$ versus photon energy $(h \nu)$ of the CdSe thin films at different $\mathrm{pH}$.

The complex refractive index of the CdSe films is described as

$$
\hat{n}=n(\lambda)+\mathrm{i} k(\lambda),
$$

where $n$ is the real part and $k$ is the imaginary part of complex refractive index. The refractive index and extinction coefficient of the films are given by the formulae

$$
\begin{aligned}
& n=\frac{1+R}{1-R}+\sqrt{\frac{4 R}{(1-R)^{2}}-k^{2},} \\
& k=\frac{\alpha \lambda}{4 \pi} .
\end{aligned}
$$

The reflectance spectra of the CdSe films are shown in Fig. 3c. The refractive index of the films is calculated using the reflectance spectra via Eq. (6) and the dependence of refractive index on wavelength is shown in Fig. 5a. It is seen from this figure that the refractive index of deposited CdSe films varies between 1.16 and 1.54, while the extinction coefficient varies between $5.1 \times 10^{-4}$ and $4.9 \times 10^{-3}$ at wavelength of $\lambda=550 \mathrm{~nm}$ in Fig. 5b. Refractive index values in the present work are much lower than the published values (2.73-2.76) [8].

The real $(\varepsilon)$ or the normal dielectric constant can be calculated by the following equation:

$$
\varepsilon=n^{2}-k^{2} \text {. }
$$
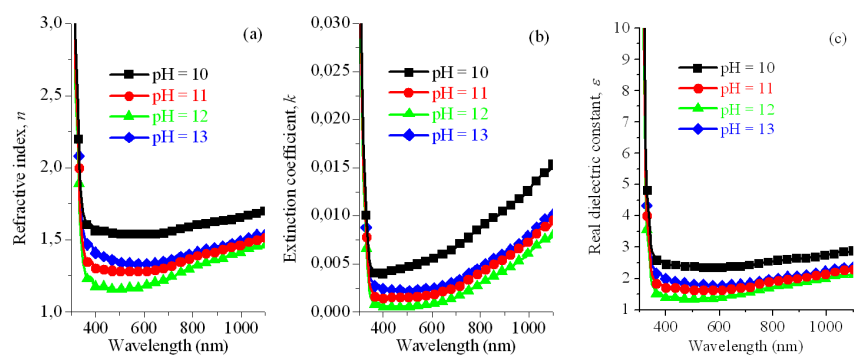

Fig. 5. Dependence of (a) refractive index, (b) extinction coefficient and (c) real dielectric constant of CdSe films on wavelength as a function of $\mathrm{pH}$.
It can be seen in Fig. 5c that the values of the real dielectric constant are nearly constant in the visible region and increase sharply near the UV region due to the strong interaction between the highly energetic photons and the charge carriers of the material. At wavelength of $550 \mathrm{~nm}$, it changes between 1.36 and 2.36 .

\section{Conclusions}

The chemical bath deposition method is used to produce CdSe thin films at $50^{\circ} \mathrm{C}$ for $3 \mathrm{~h}$ with different $\mathrm{pH}$ values in nanocrystalline with hexagonal structure. The SEM studies indicate that the CdSe film deposited at $\mathrm{pH}=10$ is well crystallized in the form of different size nanorods. The optical band width of the CdSe films increases from $1.70 \mathrm{eV}$ to $2.3 \mathrm{eV}$ with increasing $\mathrm{pH}$ for direct transition. The refractive index of the film varies between 1.16 and 1.54 at $550 \mathrm{~nm}$. Moreover, the extinction coefficient and real dielectric constant of the films vary in the range $5.1 \times 10^{-4}-4.9 \times 10^{-3}$ and $2.36-1.36$, respectively at $\lambda=550 \mathrm{~nm}$.

It can be concluded that the best preparation conditions to produce nanorods CdSe thin film is $\mathrm{pH}=10$, a bath temperature $50^{\circ} \mathrm{C}$ and immersion time of $3 \mathrm{~h}$ and these conditions makes the film suitable for technological applications such as buffer layers in solar cells.

\section{References}

[1] M-Y. Chiu, C-C. Chen, J-T. Sheu, K-H. Wei, Org. Electron. 10, 769 (2009).

[2] M.S. Al-Kotb, J.Z. Al-Waheidi, M.F. Kotkata, Superlatt. Microstruct. 69, 149 (2014).

[3] F. Li, W-N. Li, S-Y. Fu, H-M. Xiao, J. Alloy Comp. 647, 837 (2015).

[4] R.A. Potyrailo, A.M. Leach, Appl. Phys. Lett. 88, 134110 (2006).

[5] H.I. Majidi, M.E. Edley, L.C. Spangler, J.B. Baxter, Electrochim. Acta 145, 291 (2014).

[6] Y. Zhang, P. Li, W.M. Lau, Y. Gao, J. Zi, Z. Zheng, Mater. Chem. Phys. 145, 441 (2014).

[7] L. Tian, H. Yang, J. Ding, Q. Li, Y. Mu, Y. Zhang, Curr. Appl. Phys. 14, 881 (2014).

[8] Y. Akaltun, M.A. Yıldırım, A. Ateş, M. Yıldırım, Opt. Commun. 284, 2307 (2011).

[9] Q. Yang, J. Zhao, M. Guan, C. Liu, L. Cui, D. Han, Y. Zeng, Appl. Surf. Sci. 257, 9038 (2011).

[10] T.S. Shyju, S. Anandhi, R. Indirajith, R. Gopalakrishnan, J. Cryst. Growth 337, 38 (2011).

[11] Y. Zhao, Z. Yan, J. Liu, A. Wei, Mater. Sci. Semicond. Process. 16, 1592 (2013).

[12] F. Cerdeira, I. Torriani, P. Motisuke, V. Lemos, F. Decker, Appl. Phys. A 46, 107 (1988).

[13] R.H. Misho, W.A. Murad, Sol. Energy Mater. Sol. Cells 27, 335 (1992).

[14] H.M. Pathan, B.R. Sankapal, J.D. Desai, C.D. Lokhande, Mater. Chem. Phys. 78, 11 (2002).

[15] F. Göde, E. Güneri,1 F.M. Emen, V. Emir Kafadar, S. Ünlü, J. Lumin. 147, 41 (2014). 